\title{
EVALUATION OF SUNFLOWER HYBRIDS IN MULTI-ENVIRONMENT TRIAL (MET)
}

\author{
Milan JOCKOVIĆ* , Sandra CVEJIĆ, Siniša JOCIĆ, Ana MARJANOVIĆ-JEROMELA, Dragana \\ MILADINOVIĆ, Bojan JOCKOVIĆ, Vladimir MIKLIČ, Velimir RADIĆ
}

Institute of Field and Vegetable Crops, Maksima Gorkog 30, Novi Sad, SERBIA

*Corresponding author: jockovic@gmail.com

Received: 08.05.2019

\begin{abstract}
Sunflower has been proposed as a potential crop model for an adaptation to a changing environment and special attention should be paid to testing hybrids under different environments. Additive main effects and multiplicative interaction model (AMMI) supplemented with genotype main effects and genotype by environment interaction effects (GGE) were used for dissection of genotype by environment interaction and evaluation of hybrids and testing environments. The research included 24 sunflower hybrids grown across twelve environments. AMMI analysis identified four significant interaction principal components (IPC), while in GGE biplot the first two IPCs accounted together for $44.59 \%$. Environmental factors contributed the largest proportion in the total variation of seed yield $(67.40 \%)$, followed by interaction and genotypes. High yielding hybrids H1, H14 and H11 showed specific adaptation to environments E10 and E1, respectively. The average environment coordination (AEC) view of GGE biplot indicated $\mathrm{H17}$ as the most desirable genotype regarding seed yield. From the results of this study it can be concluded that MET trials are important not just for evaluation of stability and choosing the most stable genotypes, but also the genotypes that will perform well in low yielding environments and be able to take advantage of the favourable environmental conditions.
\end{abstract}

Keywords: Environmental factors, seed yield, sunflower

\section{INTRODUCTION}

Sunflower (Helianthus annuus L.) is one of the most important oil crops and preferable source of edible oil, worldwide. Besides its primary use in human consumption sunflower oil has a wide range of applications and can be used as a supplement in the chemical industry as well as in the pharmaceutical industry. Sunflower meal, a side product from oil extraction, is rich source of protein and it is efficiently utilized when blended with meal of soybean for use in the livestock feeding (Seiler and Jan, 2010). In accordance with the current forecasts scenarios of the increase in human population and climate change, it is assumed that current sunflower production is insufficient for the future needs (Radanović et al., 2018). Regarding this, sunflower has been proposed as a potential crop model for an adaptation to a changing environment and special attention should be paid to achieving high and stable yields under different conditions of cultivation. In the Balkan region, the sunflower is the most important oil crop, especially in Serbia and Romania. In the period 2012-2017 the average seed yield in Serbia was $2.63 \mathrm{t} \mathrm{ha}^{-1}$ harvested on 189217 ha with an average production of $497818 \mathrm{t}$ and in Romania average, sunflower seed yield was $2.02 \mathrm{t} \mathrm{ha}^{-1}$ with harvested area of 1030138 ha and production of $2076742 \mathrm{t}$ (FAO, 2019). The reasons why average seed yields are relatively low in both countries are that sunflower is mostly cultivated under natural conditions, without additional irrigation which effects production in years when drought stress appears.

Considering that sunflower is cultivated worldwide, one of the challengeable issues among plant breeders is genotype by environment interaction (GEI). Knowledge on the effect of environmental factors on growth and development of the crop could reduce the possibilities of significant yield loss and improve the selection of specific cultivars for growing in the target regions (MarjanovićJeromela et al., 2011). Considering that genotype is fixed while the environment shows variation through years and locations finding the most productive hybrid for specific environmental conditions is possible via testing in different environments. This procedure is essential to maximize the productivity of sunflower hybrids across environments and to provide information about genotype effect $(\mathrm{G})$, environment effect (E) and their interaction (GE). Genotype estimates across test locations, based on their discriminating ability, allows identification of megaenvironments. Mega-environments represent subset of locations that are relatively homogenous with similar biotic and abiotic stresses and cropping system requirements (Yan and Rajcan, 2002). 
There are several statistical procedures that analyse yield trials in order to help researchers to make an appropriate agronomic conclusion but the most popular approach among researchers in last decade are Additive Main effects and Multiplicative Interaction (AMMI) and Genotype Main effects and Genotype by Environment interaction effects (GGE). Both of them are based on combination of analysis of variance (AOV) and singular value decomposition (SVD) statistics also known as principal component analysis (PCA). AMMI analysis efficiently separates main effects (genotype and environment) and their interaction (GE) as essential information required for most agricultural research purposes (Gauch, 2006). Although AMMI model is efficient, GGE biplot that combines sites regression analysis (SREG) and biplot technique is very useful to identify mega-environments using the "which-wonwhere" pattern (Yan et al., 2007). GGE biplot evaluate test locations in order to identify the best performing genotypes. Several previous studies investigated GE interaction in the sunflower seed yield (De La Vega and Chapman, 2001, 2006, 2010; Branković et al., 2012; Casadebaig et al., 2016; Mijić et al., 2017). Marinković et al. (2011) concluded that the variation of seed yield in sunflower was mainly caused by location, indicating the narrow adaptability, an i.e. adaptation of genotypes to a specific environment.

Bearing in mind, agro-climatic differences in regions where sunflower is grown, the knowledge on how GEI affect the performance of a given hybrid may aid in the selection of hybrids and their suitable environments for maximum yield. Based on the consideration, the objective of the current study was to evaluate the influence of different environments on seed yield productivity of sunflower hybrids and to determine the representative and discriminative ability of testing environments.

\section{MATERIALS AND METHODS}

Genetic material

The 24 hybrids were developed by crossing 12 CMS lines and 2 restorers, during 2012 season at the breeding nursery in Rimski šančevi of the Institute of Field and Vegetable Crops. Twelve cytoplasmic male sterile (CMS) lines were developed at the Institute of Field and Vegetable Crops, Novi Sad, Serbia during the period 2000-2010. CMS lines, developed from different gene pools, represents elite sunflower lines and were selected on the basis of high seed and oil yield, high-selfcompatibility and high tolerance to diseases. Restorer lines used for creating experimental hybrids are parents of the best commercial hybrids with good combining abilities.

\section{Experimental design}

The research study was carried out at three locations in Serbia (Rimski šančevi, Šupljak and Novo Miloševo) and three locations in Romania (Teleorman, Valul lui Traian and Dalga) during 2013 and 2014 growing seasons. Genotype by environment interaction was evaluated using a combination of year and location as environments. The experiments were organized in a randomized complete block design (RCBD) with three replicates. In all environments, optimal agro-technical practices for sunflower were applied. The experimental units consisted of 4 rows with a length of $10 \mathrm{~m}$. Plant spacing was $70 \mathrm{~cm}$ between rows and $25 \mathrm{~cm}$ between plants within a row. Harvest was done by combine Wintersteiger Nurserymaster Expert. Seed yield was recorded on plants from middle rows to avoid edge effect. Seed yield was expressed in $\mathrm{kg} \mathrm{ha}^{-1}$ and adjusted to $11 \%$ moisture. Basic information of planting locations in Serbia and Romania is presented in Table 1, while in Table 2 are shown climatic data for environments in two growing seasons.

Table 1. Cite characteristics for sowing locations in Serbia and Romania

\begin{tabular}{|c|c|c|c|c|c|c|}
\hline \multirow[b]{2}{*}{ Basic data } & \multicolumn{3}{|c|}{ Serbia } & \multicolumn{3}{|c|}{ Romania } \\
\hline & $\begin{array}{l}\text { Rimski } \\
\text { šančevi }\end{array}$ & Subotica & Novo Miloševo & Teleorman & $\begin{array}{l}\text { Valul lui } \\
\text { Traian }\end{array}$ & Dalga \\
\hline Soil type & chernozem & sandy soil & $\begin{array}{c}\text { humogley + } \\
\text { salty soil }\end{array}$ & $\begin{array}{c}\text { cambic } \\
\text { chernozem } \\
\text { +vertic } \\
\text { pseudogley }\end{array}$ & $\begin{array}{c}\text { vermic } \\
\text { chernozem }\end{array}$ & $\begin{array}{c}\text { chernozem + } \\
\text { phreatic } \\
\text { water }\end{array}$ \\
\hline Climate & $\begin{array}{l}\text { continental } \\
\text { climate, with } \\
\text { cold winters } \\
\text { and hot, humid } \\
\text { summers }\end{array}$ & $\begin{array}{c}\text { continental } \\
\text { climate, with } \\
\text { cold winters } \\
\text { and hot, humid } \\
\text { summers }\end{array}$ & $\begin{array}{l}\text { continental } \\
\text { climate, with } \\
\text { cold winters } \\
\text { and hot, humid } \\
\text { summers }\end{array}$ & $\begin{array}{l}\text { wet, } \\
\text { temperate } \\
\text { continental } \\
\text { climate }\end{array}$ & $\begin{array}{l}\text { mixed climate } \\
\text { between wet } \\
\text { and warm } \\
\text { continental and } \\
\text { warm oceanic }\end{array}$ & $\begin{array}{c}\text { wet, } \\
\text { temperate } \\
\text { continental } \\
\text { climate }\end{array}$ \\
\hline \multirow{2}{*}{ Coordinates } & $45^{\circ} 20^{\prime} \mathrm{N}$ & $46^{\circ} 06^{\prime} \mathrm{N}$ & $45^{\circ} 72^{\prime} \mathrm{N}$ & $44^{\circ} 07^{\prime} \mathrm{N}$ & $44^{\circ} 10^{\prime} \mathrm{N}$ & $44^{\circ} 26^{\prime} \mathrm{N}$ \\
\hline & $19^{\circ} 51^{\prime} \mathrm{E}$ & $19^{\circ} 40^{\prime} \mathrm{E}$ & $20^{\circ} 30^{\prime} \mathrm{E}$ & $25^{\circ} 45^{\prime} \mathrm{E}$ & $28^{\circ} 29^{\prime} \mathrm{E}$ & $27^{\circ} 40^{\prime} \mathrm{E}$ \\
\hline
\end{tabular}


Table 2. Planting locations, environments and climatic data for 2013 and 2014 growing seasons

\begin{tabular}{|c|c|c|c|c|c|c|c|c|c|}
\hline \multirow{2}{*}{ Location } & \multirow{2}{*}{ environment } & \multirow{2}{*}{$\begin{array}{l}\text { Rain } \\
(\mathbf{m m})\end{array}$} & \multicolumn{6}{|c|}{ Average monthly temperature } & \multirow{2}{*}{ Mean } \\
\hline & & & IV & $\mathbf{V}$ & VI & VII & VIII & IX & \\
\hline \multirow{2}{*}{ Rimski šančevi } & E1 2013 & 445 & 13 & 17 & 20 & 22 & 23 & 16 & 18.5 \\
\hline & E7 2014 & 644 & 13 & 16 & 21 & 22 & 21 & 17 & 18.3 \\
\hline \multirow{2}{*}{ Subotica } & E2 2013 & 296 & 13 & 19 & 21 & 22 & 24 & 15 & 19.0 \\
\hline & E8 2014 & 563 & 13 & 16 & 21 & 23 & 21 & 17 & 18.5 \\
\hline \multirow{2}{*}{ Novo Miloševo } & E3 2013 & 292 & 14 & 20 & 22 & 24 & 25 & 17 & 20.3 \\
\hline & E9 2014 & 425 & 13 & 16 & 20 & 22 & 21 & 17 & 18.2 \\
\hline \multirow{2}{*}{ Teleorman } & E4 2013 & 314 & 14 & 19 & 22 & 23 & 24 & 17 & 19.8 \\
\hline & E10 2014 & 452 & 12 & 16 & 20 & 23 & 23 & 18 & 18.7 \\
\hline \multirow{2}{*}{ Valu lui Traian } & E5 2013 & 102 & 13 & 19 & 24 & 23 & 24 & 19 & 20.3 \\
\hline & E11 2014 & 430 & 12 & 17 & 20 & 23 & 24 & 19 & 19.2 \\
\hline \multirow{2}{*}{ Dalga } & E6 2013 & 253 & 14 & 20 & 23 & 24 & 25 & 18 & 20.7 \\
\hline & E12 2014 & 287 & 13 & 18 & 21 & 25 & 27 & 19 & 20.5 \\
\hline
\end{tabular}

\section{Statistical analysis}

Additive main effect and multiplicative interaction (AMMI) method that combines the traditional ANOVA and principal component analysis (PCA) into a single analysis as proposed by Zobel et al. (1988) was used to analyze genotype effect $(G)$, environment effect $(E)$ and their interaction (GE).

$$
Y_{g e}=\mu+\alpha_{g}+\beta_{e}+\sum \lambda_{n} \xi_{g n} \eta_{e n}+\theta_{g e}
$$

Where:

$$
\begin{aligned}
& Y_{g e} \text { - yield of genotype } g \text { in environment } e \\
& \mu \text { - grand mean } \\
& \alpha_{g} \text { - mean deviation of the genotype } \\
& \beta_{e}-\text { mean deviation of the environment } \\
& \lambda_{n}-\text { singular value for PCA axis } n \\
& \xi_{g n}-\text { genotype eigenvector for PCA axis } n \\
& \eta_{e n}-\text { environment eigenvector for PCA axis } n \\
& \theta_{g e}-\text { residues, including experimental error }
\end{aligned}
$$

The AMMI biplot is constructed by plotting the scores of GE interactions that are placed on the ordinate (IPC1) and genotype and environmental means that are placed on the abscissa. In the biplot, genotype and environment main effects, genotype stability and adaptability to different environments are visualized. F-test was used to test the statistical significance of sources of variation.

For identification of the mega-environments using the „which-won-where“ pattern GGE biplot was constructed. The method was developed by Yan and Kang (2003) and allows an environment-centered matrix containing the GGE data to be subjected to singular value decomposition. The GGE biplot graphically displays G plus GE of the MET data in a way that facilitates visual variety evaluation and mega-environment identification (Yan, 2014).
Following equation is used to estimate each element in the matrix:

$$
\mathrm{Y}_{\mathrm{ij}}=\mu+\beta_{\mathrm{j}}+\lambda_{1} \xi_{\mathrm{i} 1} \eta_{\mathrm{j} 1}+\lambda_{2} \xi_{\mathrm{i} 2} \eta_{\mathrm{j} 2}+\varepsilon_{\mathrm{ij}}
$$

Where:

Yij is the trait mean for genotype $\mathrm{i}$ in environment $\mathrm{j}$

$\mu$ is the general mean

$\beta_{\mathrm{j}}$ represents the environment main effect

$\mu+\beta_{\mathrm{j}}$ represents the mean yield across all genotypes in environment $\mathrm{j}$

$\lambda_{1}$ and $\lambda_{2}$ are the singular values for the first and second PCs PC2

$\xi_{\mathrm{i} 1}$ and $\xi_{\mathrm{i} 2}$ are eigenvectors of genotype i for PC1 and

$\eta_{\mathrm{j} 1}$ and $\eta_{\mathrm{j} 2}$ are eigenvectors of environment $\mathrm{j}$ for PC1 and $\mathrm{PC} 2$

$\varepsilon_{\mathrm{ij}}$ is the residual associated with genotype $\mathrm{i}$ in environment $\mathrm{j}$

\section{RESULTS AND DISCUSSION}

Investigation of developed promising genotypes in different environments is one of the most challengeable tasks for plant breeders. Reliable estimation of the extent to which genotype by environment interaction (GEI) affects a trait of interest is an important determinant for the evaluation and selection of genotypes, especially for target regions. In order to obtain reliable information about GEI effect, it is necessary to organize a multienvironment trial. Multi-environment trial should include environments that have different agro-climatic characteristics in order to obtain a more reliable estimation of tested genotypes.

Like previously stated by Kaya (2014), sunflower is one of the most important oil crops that can be grown in many parts of the world because of ability to be cultivated in generally dry and rained conditions. As it can be seen from the climatic table in the study yearly variations are caused mainly by precipitation (Table 2). The exception is only locality Dalga wherein both years climatic conditions 
were relatively constant with precipitation lower than 300 $\mathrm{mm}$. It is evident that precipitation was higher in 2014 growing season in all environments. Higher amounts of rainfall had an influence on disease pressure and percent of fertilization during the flowering time which resulted in lower yields in almost all environments during 2014 growing season. Supporting results of the current paper, Del Gatto et al. (2015) reported that during 3 year period sunflower hybrids tested in Northern Italy had higher yields in a year with less precipitation. When comparing environments, precipitation ranged between $102 \mathrm{~mm}$ (E5) and $644 \mathrm{~mm}$ (E7). The average temperature during the vegetation period varied between $18.17^{\circ} \mathrm{C}$ (E9) and 20.67 ${ }^{\circ} \mathrm{C}$ (E6). Higher amounts of rainfall have contributed to lower average temperatures in all environments during 2014 growing season. Also, differences in soil type on each location indicated the presence of diverse environmental conditions. Considering environmental factors, the influence of soil type can be minimized by doing analysis and adding an adequate amount of nutrients across locations, but climatic factors during the year, distribution of rainfall and sum of temperatures are not repeatable. In a previous study Romay et al. (2010) highlighted the significance of climatic conditions on seed yield in maize.

AMMI analysis provides us valuable information and estimation of genotype performance, significant for the development of high yielding genotypes in specific environment (Hristov et al., 2010). In crop production, yield stability is considered the most important socioeconomic category, especially in extreme environmental conditions (Ceccareli, 1994; Piepho, 1998). Because of that, it is fundamental to grow stable cultivars with good seed and oil yields in diverse agro-ecological conditions (Moghaddam and Pourdad, 2011). AMMI analysis of variance gives a clear insight into differences between hybrids and environments observed in this study (Table 3). AMMI analysis of variance showed that in the total variation of the experiment additive effects, genotype (G) and environment (E), as well as their interaction (GEI) was statistically significant (Table 3 ). Regarding additive effects, $G$ and $E$ accounted together for $74.95 \%$, while their interaction accounted for $25.05 \%$, in treatment sum of squares. Environmental factors contributed the largest proportion in the total variance of the experiment which is in agreement with the earlier statement that in multienvironment trials the main portion of the variability in yield is caused by the environment (Yan, 2001; Mohammadi and Amri, 2013; Oliveira et al., 2014). AMMI analysis partitioned GE interaction into four principal components which accounted together for $69.97 \%$. The first principal component (IPC1), which is caused by the effect of genotype and environment, explained the largest part $(28.45 \%)$ of the total variability in interaction, for seed yield.

Table 3. AMMI analysis of variance

\begin{tabular}{lccccc}
\hline \multicolumn{1}{c}{ Source } & degrees of freedom & Sum of squares & Mean squares & \multicolumn{3}{c}{ Variation explained } \\
$(\%)$
\end{tabular}

$* \mathrm{P}<0.05 ; * * \mathrm{P}<0.01$

Observing the overall average productivity of tested sunflower hybrids across 12 environments seed yield varied from $3452 \mathrm{~kg} \mathrm{ha}^{-1}$ for hybrid $\mathrm{H} 10$ to $4263 \mathrm{~kg} \mathrm{ha}^{-1}$ recorded for hybrid H17 (Table 4). Also, hybrids H1, H14 and H11 were distinguished from others in terms of productivity by higher average yield than the overall mean. Environment E4 was the highest yielding environment with an average seed yield of $5044 \mathrm{~kg} \mathrm{ha}^{-1}$, while the lowest yielding environment was E9 $(2565 \mathrm{~kg}$ $\mathrm{ha}^{-1}$ ). Besides E4, environments E8, E1, E7, E3 and E10 recorded higher average yields than the overall average and can be classified as high yielding environments, while environments E2, E5, E6, E11 and E12 can be considered as low yielding environments compared to the overall average. 
Table 4. AMMI average values of sunflower seed yield $\left(\mathrm{kg} \mathrm{ha}^{-1}\right)$ across environments

\begin{tabular}{|c|c|c|c|c|c|c|c|c|c|c|c|c|c|c|c|c|c|c|c|}
\hline \multirow{3}{*}{ Genotype } & \multicolumn{9}{|c|}{2013} & \multicolumn{9}{|c|}{2014} & \multirow{3}{*}{$\begin{array}{c}2013 \text { / } 2014 \\
\text { Avg. }\end{array}$} \\
\hline & \multicolumn{4}{|c|}{ Serbia } & \multicolumn{4}{|c|}{ Romania } & \multirow{2}{*}{$\begin{array}{c}2013 \\
\text { Mean }\end{array}$} & \multicolumn{4}{|c|}{ Serbia } & \multicolumn{4}{|c|}{ Romania } & \multirow{2}{*}{$\begin{array}{c}2014 \\
\text { Mean }\end{array}$} & \\
\hline & E1 & E2 & E3 & Mean & E4 & E5 & E6 & Mean & & E7 & E8 & E9 & Mean & E10 & E11 & E12 & Mean & & \\
\hline $\mathrm{H} 1$ & 4762 & 3802 & 4254 & 4273 & 5178 & 4083 & 3948 & 4403 & 4338 & 4605 & 4497 & 3084 & 4062 & 4432 & 3791 & 3658 & 3960 & 4011 & 4175 \\
\hline $\mathrm{H} 2$ & 3991 & 4201 & 4221 & 4138 & 5686 & 3717 & 4187 & 4530 & 4334 & 4357 & 4793 & 2395 & 3848 & 3790 & 3699 & 3832 & 3774 & 3811 & 4073 \\
\hline H3 & 4339 & 3996 & 4071 & 4135 & 4732 & 3779 & 3711 & 4074 & 4105 & 4001 & 4089 & 2234 & 3441 & 4039 & 3676 & 3672 & 3796 & 3619 & 3862 \\
\hline $\mathrm{H} 4$ & 3932 & 3373 & 3633 & 3646 & 5060 & 3319 & 3710 & 4030 & 3838 & 4513 & 4437 & 2676 & 3875 & 3546 & 3917 & 3135 & 3533 & 3704 & 3771 \\
\hline H5 & 4725 & 3689 & 4723 & 4379 & 5153 & 4069 & 3996 & 4406 & 4393 & 4212 & 4548 & 2852 & 3871 & 3913 & 3287 & 3592 & 3597 & 3734 & 4063 \\
\hline H6 & 3914 & 3759 & 4150 & 3941 & 5500 & 3582 & 3952 & 4345 & 4143 & 4129 & 4603 & 2377 & 3703 & 3565 & 3187 & 3499 & 3417 & 3560 & 3851 \\
\hline H7 & 4386 & 3661 & 4318 & 4122 & 4541 & 3697 & 3655 & 3964 & 4043 & 3846 & 4086 & 2258 & 3397 & 3597 & 3477 & 3428 & 3501 & 3449 & 3746 \\
\hline $\mathrm{H} 8$ & 4347 & 3524 & 4385 & 4085 & 4692 & 3640 & 3740 & 4024 & 4055 & 3979 & 4271 & 2414 & 3555 & 3407 & 3511 & 3330 & 3416 & 3486 & 3770 \\
\hline H9 & 4290 & 4016 & 3805 & 4037 & 4707 & 3821 & 3533 & 4020 & 4029 & 3859 & 3842 & 2133 & 3278 & 4401 & 3317 & 3694 & 3804 & 3541 & 3785 \\
\hline $\mathrm{H} 10$ & 3602 & 3726 & 3642 & 3657 & 4511 & 3137 & 3469 & 3706 & 3682 & 3670 & 3921 & 1635 & 3075 & 3206 & 3612 & 3289 & 3369 & 3222 & 3452 \\
\hline H11 & 4653 & 3355 & 4404 & 4137 & 5293 & 3914 & 3969 & 4392 & 4265 & 4627 & 4695 & 3262 & 4195 & 3912 & 3539 & 3327 & 3593 & 3894 & 4079 \\
\hline H12 & 4028 & 3021 & 3932 & 3660 & 5420 & 3444 & 3781 & 4215 & 3938 & 4491 & 4647 & 3001 & 4046 & 3462 & 3186 & 2971 & 3206 & 3626 & 3782 \\
\hline $\mathrm{H} 13$ & 5282 & 3255 & 4530 & 4356 & 4145 & 4099 & 3601 & 3948 & 4152 & 4377 & 4055 & 3209 & 3880 & 4120 & 3959 & 3264 & 3781 & 3831 & 3991 \\
\hline H14 & 4733 & 3786 & 3825 & 4115 & 4709 & 3920 & 3713 & 4114 & 4115 & 4674 & 4185 & 2985 & 3948 & 4547 & 4323 & 3565 & 4145 & 4047 & 4080 \\
\hline H15 & 4004 & 3848 & 3679 & 3844 & 4990 & 3549 & 3674 & 4071 & 3958 & 4176 & 4180 & 2290 & 3549 & 3987 & 3658 & 3512 & 3719 & 3634 & 3796 \\
\hline H16 & 4167 & 3970 & 4237 & 4125 & 4911 & 3664 & 3842 & 4139 & 4132 & 3971 & 4298 & 2156 & 3475 & 3644 & 3637 & 3632 & 3638 & 3557 & 3844 \\
\hline H17 & 4869 & 3663 & 4138 & 4223 & 5253 & 4100 & 3973 & 4442 & 4333 & 4929 & 4605 & 3435 & 4323 & 4573 & 4044 & 3571 & 4063 & 4193 & 4263 \\
\hline H18 & 4345 & 3597 & 3801 & 3914 & 5391 & 3948 & 3647 & 4329 & 4122 & 4219 & 4204 & 2805 & 3743 & 4632 & 2699 & 3494 & 3608 & 3676 & 3899 \\
\hline H19 & 4348 & 3281 & 4439 & 4023 & 4985 & 3723 & 3719 & 4142 & 4083 & 3921 & 4333 & 2599 & 3618 & 3502 & 2829 & 3216 & 3182 & 3400 & 3741 \\
\hline $\mathrm{H} 20$ & 3711 & 3511 & 4249 & 3824 & 5364 & 3436 & 3783 & 4194 & 4009 & 3658 & 4428 & 2050 & 3379 & 3161 & 2507 & 3297 & 2988 & 3184 & 3596 \\
\hline $\mathrm{H} 21$ & 4737 & 3600 & 4275 & 4204 & 4905 & 4139 & 3603 & 4216 & 4210 & 3936 & 4020 & 2716 & 3557 & 4509 & 2695 & 3540 & 3581 & 3569 & 3890 \\
\hline $\mathrm{H} 22$ & 4569 & 3658 & 4437 & 4221 & 5343 & 4048 & 3902 & 4431 & 4326 & 4193 & 4471 & 2841 & 3835 & 4171 & 2937 & 3572 & 3560 & 3698 & 4012 \\
\hline $\mathrm{H} 23$ & 4157 & 3177 & 3998 & 3777 & 5153 & 3650 & 3568 & 4124 & 3951 & 3977 & 4221 & 2647 & 3615 & 3810 & 2542 & 3128 & 3160 & 3388 & 3669 \\
\hline $\mathrm{H} 24$ & 3467 & 3997 & 3934 & 3799 & 5444 & 3498 & 3665 & 4202 & 4001 & 3303 & 4117 & 1514 & 2978 & 3654 & 2114 & 3632 & 3133 & 3056 & 3528 \\
\hline Average & 4307 & 3645 & 4128 & 4027 & 5044 & 3749 & 3764 & 4186 & 4107 & 44151 & 4314 & 2565 & 3677 & 3899 & 3339 & 3452 & 3563 & 3620 & 3863 \\
\hline $\mathrm{CV}(\%)$ & $16 \%$ & $16 \%$ & $13 \%$ & & $9 \%$ & $11 \%$ & $5 \%$ & & & $18 \%$ & $9 \%$ & $27 \%$ & & $15 \%$ & $23 \%$ & $11 \%$ & & & $21 \%$ \\
\hline LSD (0.05) & 994.1 & 937.8 & 757.8 & & 413.1 & 257.3 & 229.1 & & & 1103 & 596.3 & 799 & & 637.5 & 1022 & 356.9 & & & 368.3 \\
\hline
\end{tabular}


For a clearer explanation of the main effects and their interaction biplot is constructed for evaluation of stability and adaptability (Figure 1). Average values of the main effects ( $\mathrm{Gx}$ and Ex) were entered on the abscissa, while IPC1 values (IPCg and IPCe) were plotted on the ordinate. Values plotted on abscissa control the wide sense adaptability, while IPCA values (ordinate) control the narrow sense adaptability (Gauch and Zobel, 1997). Reliable estimation of genotype productivity is essential in order for identifying genotypes capable for the highest productivity in specific environments, i.e. genotypes for target environments. Earlier studies emphasize the importance of GEI for creating genotypes adopted to target areas and implementing AMMI model in order to increase accuracy (Fox et al., 1997; Marjanović-Jeromela et al., 2008; Gauch, 2013).

As presented in Figure 1 genotypes and environments positioned around abscissa showed the low effect of interaction, i.e. demonstrated wide adaptability. Left and right position of genotypes and environments in relation to the vertical line, which represents overall mean, demonstrated lower and higher average performance. Among twelve environments, Valu lui Traian in 2013 (E5) demonstrated the highest stability for production because of the lowest IPC1 value. In contrast, Teleorman E4, Subotica (E8) and Rimski šančevi (E1) were high yielding environments but also demonstrated the highest interaction values and are defined as unstable environments considering seed yield. Unfavorable environments, distinguished with lower average yields and high level of interaction, were E9 and E11. Regarding sunflower hybrids genotype H5 was distinguished from other hybrids with the lowest interaction value and high seed yield and is considered more resilient to differences in environmental conditions. Bearing in mind that random nature of the year-dependent factors which causes yearly variations makes environmental factors generally unpredictable, for stable and profitable sunflower production focus should be on hybrids with high genetic yield potential, wide adaptability and yield stability.

Observing genotype position on AMMI biplot it can be seen that hybrids $\mathrm{H} 24$ and $\mathrm{H} 13$ were differentiated by the highest values of GE interaction and these are the most unstable hybrids identified. Furthermore, the position of hybrids on biplot indicates positive interaction with certain environments as hybrids positioned above abscissa had positive interaction with environments E2, E3, E4, E6, E8 and E12 and vice versa. Genotypes positioned bellow abscissa had positive interaction with environments E1, E5, E7, E9, E10 and E11. Results of AMMI biplot also indicated that the highest yielding hybrids had a specific adaptation to certain environments. For instance, hybrid H17 showed high interaction values and a specific adaptation to high yielding environments E1 and E7. High yielding hybrids H1, H14 and H11 showed specific adaptation to environments E10 and E1, respectively. These genotypes also performed very good in low yielding environments E9 and E11. Furthermore, hybrid $\mathrm{H} 2$ showed specific adaptation and achieved the highest yields in environments with low precipitation such as E2, E4, E6 and E12. In accordance with the study, several previous studies evaluated adaptability and stability of genotypes and concluded that high yielding genotypes have specific adaptability in certain environments (da Silveira et al., 2013; Temesgen et al., 2014; Nowosad et al., 2016).

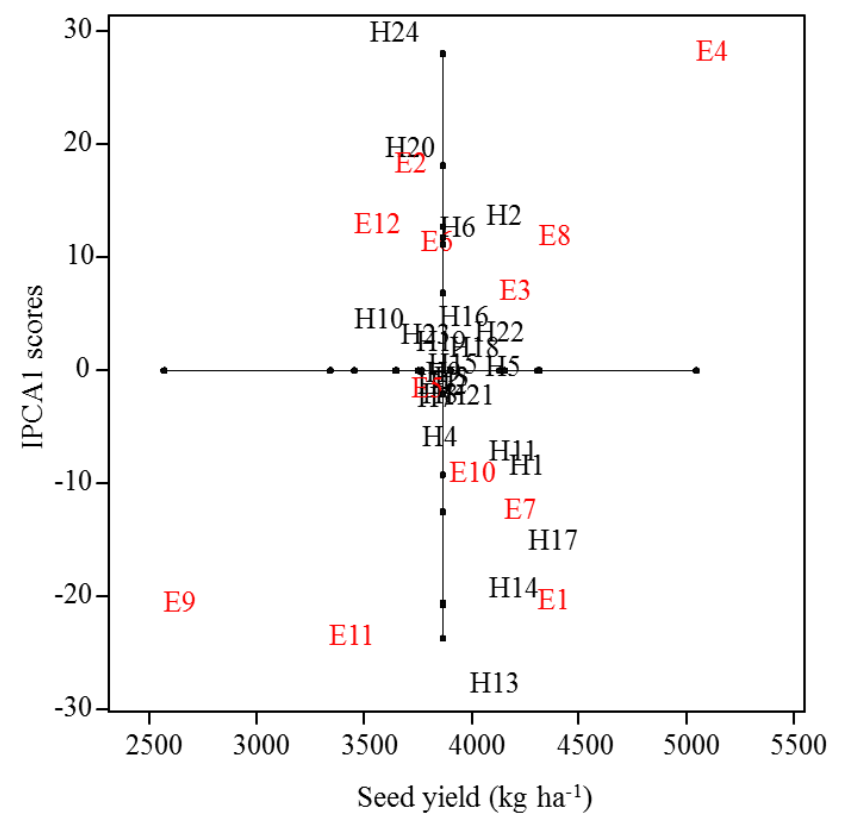

Figure 1. AMMI biplot for GEI based on IPC1 scores

Identification of "ideal" testing environment is important in plant breeding in order to rationalize resources and confine genotype testing to sites which will give informative data thereby facilitating a rapid response to the selection. Mega-environments allow identification of the most discriminative and representative environments that are considered "ideal" for the evaluation of general and specific adaptation of tested genotypes. Favorable test environments are characterized with high IPC1 values and low IPC2 (interaction) values (Hassani et al., 2018).

The which-won-where polygon of GGE biplot is helping in the visualization of representativeness and discriminative ability of environments by comparison of the distance between genotypes and environments (Figure 2 ). Polygon is created by drawing the lines between the furthest hybrids in the biplot. The lines which start from the coordinate origin are perpendicular to the sides of the polygon dividing the polygon into sectors in which different mega-environments can be detected (Yan and Tinker, 2006). Environments sharing a single sector have the same hybrid as the best and they may be considered as a mega-environment (Stojaković et al., 2015). The equality line divided the test environments into four megaenvironments for sunflower seed yield, as environments that share a single sector have the same hybrid as the best one and they are considered as a mega-environment. The 
first mega-environment was identified as E2, while the second mega-environment consisted of E1, E5, E10, E11 and E12. As the third mega-environment group of three environments E3, E7 and E9 were identified. Environments E4, E6 and E8 were identified as the fourth mega-environment. Although "which-won-where" model formed four mega-environments it can be seen that there is no logical grouping pattern, meaning that the most of locations in different years of testing showed positive and negative PC1 scores which made a group change depending on the year. Regarding this, Yan (2014) defined that GEI which is dominated by GLY (genotype $\mathrm{x}$ location $\mathrm{x}$ year) interaction cannot divide target regions into mega-environments as the target environment represents single but complex mega-environment and for proper evaluation of genotype productivity multi-year and multi-location trials are necessary. Which means that it is not sufficient to run trials in a single, "ideal" location, because such a location does not exist, but rather in a number of locations in order to cover as many environments as possible.

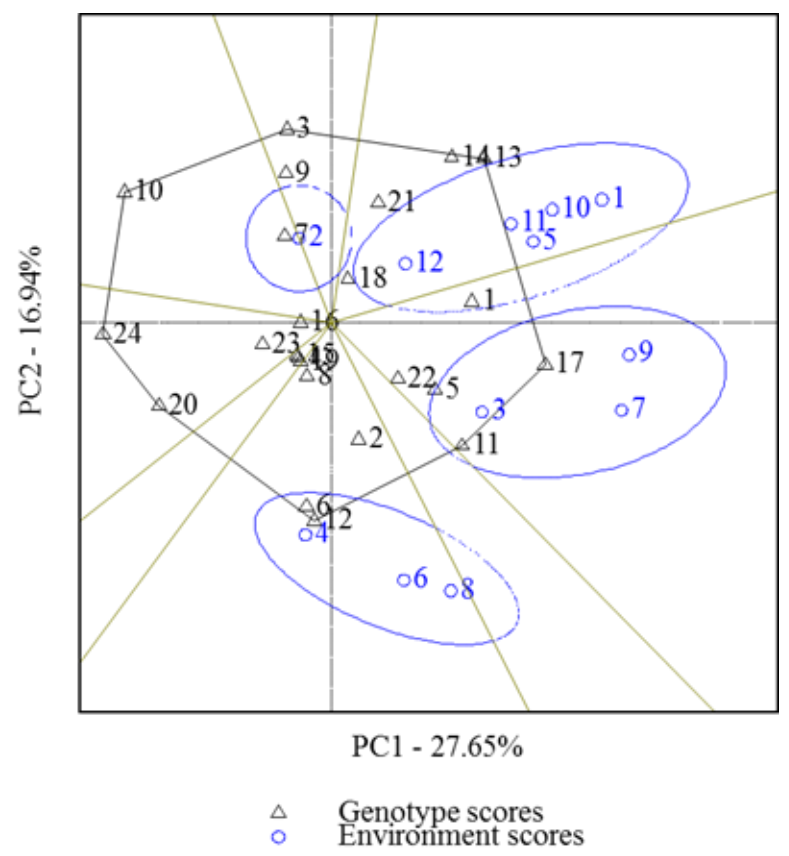

Figure 2. Which-won-where polygon view of the GGE biplot of genotypes and environments

Representativeness of test environments is presented by concentric circles that help in visualizing the distance between each environment and average environment (Figure 3). The average environment presents the average performance of the target environment and it is presented by the centre of the concentric circles (Yan and Kang, 2003; Jandong et al., 2011).

Bearing in mind that the environment that is closest to the center of the concentric circles is the most representative the present study has shown that E7 and E9 are the most representative. Also, in GGE biplot the concentric circles helps to identify an ideal genotype for a trait of interest. The center of concentric circles represents the position of an "ideal" genotype. It equals the longest vector of the genotypes that had above average mean yields and by a zero projection onto the perpendicular line. The ideal genotype is considered one which at the same time has high average yield and high stability. The average environment coordination (AEC) view of GGE biplot indicated that H17 was the closest to the "ideal" genotype and was accordingly identified as the most desirable genotype with respect to seed yield. In terms of "ideal" genotype, although such genotype may not exist in reality, it can be used as a reference for genotype evaluation (Solonechnyi et al., 2015).

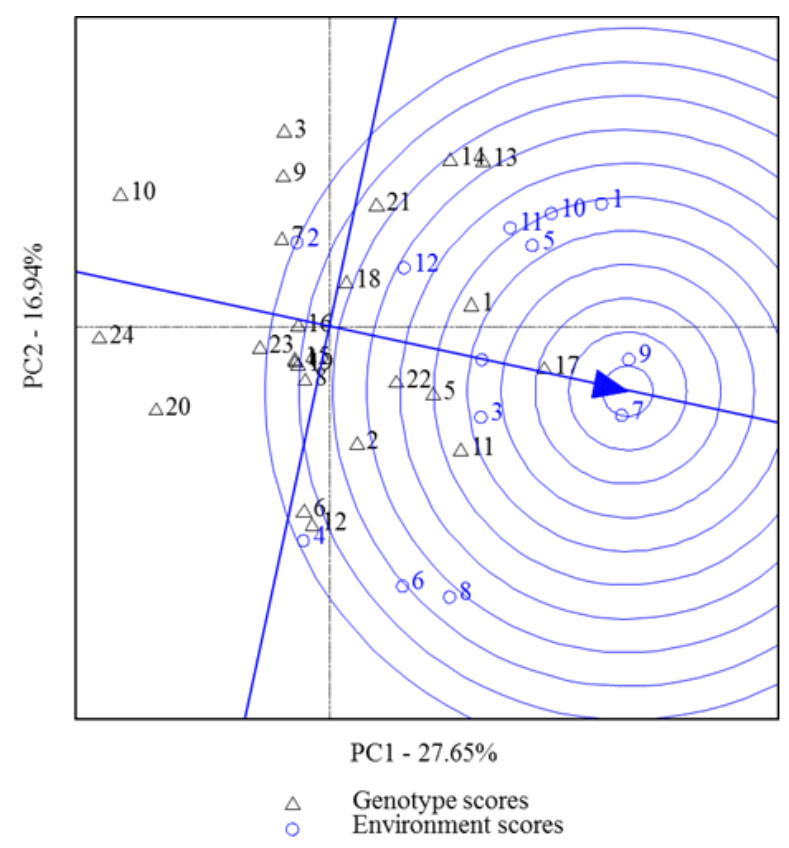

Figure 3. Genotype ranking within environments and representativeness of test environments

The discriminative ability of test environments is presented in Figure 4 and it is based on the length of the vectors formed by each environment which presents standard deviation of genotype within each environment. Environments with short vectors have low discriminating power and they are not informative as genotypes react similarly in it. Hence, environments E2, E12 and E3 had low discriminating power, while environments E1, E7, E8 and E9 were the most discriminative.

Combining the results presented in Figures 3 and 4 environments E7 and E9 can be identified as the most "ideal" as they are both the most representative and discriminative. Furthermore, results are indicating that there is no logical grouping pattern regarding the representative and discriminative ability of test environments. The same locations in different years had a different position in relation to the center of concentric circles and the position and length of the vectors in relation to the "ideal" location, which indicates no repeatable pattern. 


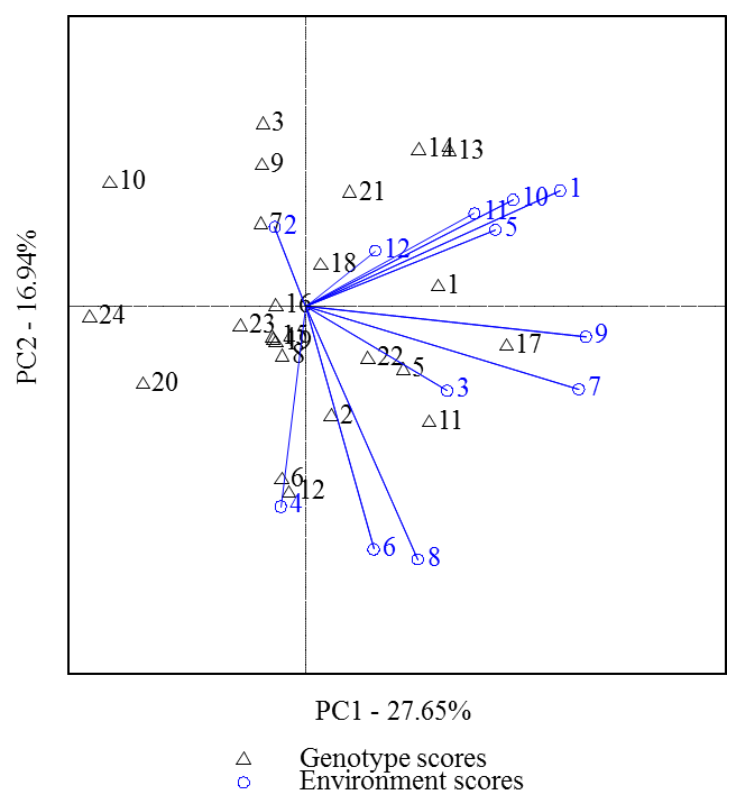

Figure 4. GGE biplot vector view indicating discriminative abilities of tested environments

\section{CONCLUSIONS}

Combining the AMMI and GGE is very useful for obtaining reliable information about adaptability and stability of genotypes, as well as discriminating ability and representativeness of test environments. Variation in productivity of sunflower hybrids was significantly affected by differences in environment, followed by genotype by environment interaction and diversity in genotypes. Bearing in mind that "ideal" genotype in general is considered to have high and stable seed yield across different environments, specific adaptation to certain environments (i.e. high positive interaction values) is also desirable as ability of genotype to fully utilize favorable environmental conditions. The highest yielding hybrids H17, H1, H14 and H11 showed specific adaptation to favorable environments. Althought AMMI analysis showed that hybrid H17 expressed high interaction values, average environment coordination view of GGE biplot indicated that $\mathrm{H} 17$ was the most desirable sunflower hybrid as it was closest to the "ideal". Hybrid H5 was differentiated from other hybrids with the highest stability accompanied by high seed yield and is considered more resilient to differences in environmental conditions. Graphical visualization of GGE biplot demonstrated that four mega-environments were formed. Analysing representativeness and discriminating ability of the test environments this study identified environments E7 and E9 as the most "ideal". From the results of this study it can be concluded that MET trials are important not just for evaluation of stability and choosing the most stable genotypes, but also the genotypes that will perform well in low yielding environments and be able to take advantage of the favorable environmental conditions.

\section{ACKNOWLEDGMENTS}

This research is part of the project TR-31025, funded by the Ministry of Education, Science and Technological
Development of the Republic of Serbia, provincial Secretariat for Higher Education and Science of Vojvodina, project 114-451-2126/2016-03 as well as a bilateral project between Serbia and Germany 451-0301732/2017-09/3 and COST Action CA 16212. Special thanks to Mr. Ilija Radeka and his team for efforts in carrying out the experiment.

\section{LITERATURE CITED}

Branković, G., I. Balalić, M. Zorić, V. Miklič, S. Jocić and G. Šurlan-Momirović. 2012. Characterization of sunflower testing environments in Serbia. Turkish Journal of Agriculture and Forestry 36 (3): 275-283.

Casadebaig, P., E. Mestries and P. Debakey. 2016. A modelbased approach to assist variety evaluation in sunflower crop. European Journal of Agronomy 81: 92-105.

Ceccareli, S. 1994. Specific adaptation and breeding for marginal conditions. Euphytica 77: 205-219.

da Silveira, L.C.I., V. Kist, T.O.M. de Paula, M.H.P. Barbosa, L.A. Peternelli and E. Daros. 2013. Ammi analysis to evaluate the adaptability and phenotypic stability of sugarcane genotypes. Scientia Agricola 70 (1): 27-32.

De La Vega, A.J. and S.C. Chapman. 2001. Genotype by environment interaction and indirect selection for seed yield in sunflower, II. Three-mode principal component analysis of oil and biomass yield across environments in Argentina. Field Crops Research 72 (1): 39-50.

De La Vega, A.J. and S.C. Chapman. 2006. Defining sunflower selection strategies for a highly heterogeneous target population of environments. Crop Sci. 46 (1): 136-144.

De La Vega, A.J. and S.C. Chapman. 2010. Mega-environment differences affecting genetic progress for yield and relative value of component traits. Crop Sci. 50 (2): 574-583.

Del Gatto, A., C. Mengarelli, E. Foppa Pedretti, D. Duca, S. Pieri, L. Mangoni, M. Signor, S.A. Raccuia and M.L. Melilli. 2015. Adaptability of sunflower (Helianthus annuus L.) high oleic hybrids to different Italian areas for biodiesel production. Industrial Crops and Products, 75A: 108-117.

FAO. 2019: http://www.fao.org/faostat/en/\#data/QC(accessed 14.04.2019)

Fox, P.N., J. Crossa and I. Ramagossa. 1997. Multienvironmental testing and genotype $\mathrm{x}$ environment interaction. In: Statistical Methods for Plant Variety Evaluation, ed. Kempton, R.A. and Fox, P.N., 117-138, Chapman \& Hall, London.

Gauch, H.G. and R.W. Zobel. 1997. Identifying megaenvironments and targeting genotypes. Crop Sci. 37 (2): 311326.

Gauch, H.G. 2006. Statistical analysis of yield trials by AMMI and GGE. Crop Sci. 46 (4): 1488-1500.

Gauch, H.G. 2013. A Simple Protocol for AMMI Analysis of Yield Trials. Crop Sci. 53 (5): 1860-1869.

Hassani, M., B. Heidari, A. Dadkhodaie and P. Stevanato. 2018. Genotype by environment interaction components underlying variations in root, sugar and white sugar yield in sugar beet (Beta vulgaris L.). Euphytica 214 (4): 79.

Hristov, N., N. Mladenov, V. Đurić, A. Kondic-Spika, A. Marjanović-Jeromela and D. Simić. 2010. Genotype by environment interactions in wheat quality breeding programs in southeast Europe. Euphytica 174: 315-324.

Jandong, E.A., M.I. Uguru and B.C. Oyiga. 2011. Determination of stability of Soybean (Glycine max) genotypes across diverse soil $\mathrm{pH}$ levels using GGE Biplot analysis. Journal of applied Biosciences 43: 2924-2941. 
Kaya, Y. 2014. Sunflower Production in Balkan Region: Current Situation and Future prospects. Agriculture and Forestry 60 (4): 95-101.

Marinković, R., M. Jocković, A. Marjanović-Jeromela, S. Jocić, M. Ćirić, I. Balalić and Z. Sakač. 2011. Genotype by environment interactions for seed yield and oil content in sunflower (H. annuus L.) using AMMI model. Helia 34(54): 79-88.

Marjanović-Jeromela, A., R. Marinković, A. Mijić, M. Jankulovska, Z. Zdunić and N. Nagl. 2008. Oil Yield Stability of Winter Rapeseed (Brassica napus L.) Genotypes. Agriculturae Conspectus Scientificus 73 (4): 217-220.

Marjanović-Jeromela, A., N. Nagl, J. Gvozdanović-Varga, N. Hristov, A. Kondić-Špika, M. Vasić and R. Marinković. 2011. Genotype by environment interaction for seed yield per plant in rapeseed using AMMI model. Pesquisa Agropecuária Brasileira 46 (2): 174-181.

Mijić, A., I. Liović, A. Sudarić, D. Gadžo, Z. Jovović, M Jankulovska, A. Markulj-Kulundžić and T. Duvnjak. 2017. The effect of environment on the phenotypic expression of grain yield, oil content and oil yield in sunflower hybrids. Agriculture and Forestry 63 (1): 309-318

Moghaddam, M.J. and S.S. Pourdad. 2011. Genotype x environment interactions and simultaneous selection for high oil yield and stability in rainfed warm areas rapeseed (Brassica napus L.) from Iran. Euphytica 180 (3): 321-335.

Mohammadi, R. and A. Amri. 2013. Genotype x environment interaction and genetic improvement for yield and yield stability of rainfed durum wheat in Iran. Euphytica 192 (2): 227-249.

Nowosad, K., A. Liersch, W. Poplawska and J. Bocianowski. 2016. Genotype by environment interaction for seed yield in rapeseed (Brassica napus L.) using additive main effects and multiplicative interaction model. Euphytica 208 (1): 187194.

Oliveira, E.J., J.P.X. Freitas and O.N. Jesus. 2014. AMMI analysis of the adaptability and yield stability of yellow passion fruit varieties. Scientia Agricola 71 (2): 139-145.

Piepho, H.P. 1998. Methods for comparing the yield stability of cropping system - a review. Journal of Agronomy and Crop Science 190: 193-21.

Radanović, A., D. Miladinović, S. Cvejić, M. Jocković and S. Jocić. 2018. Sunflower Genetics from Ancestors to Modern Hybrids - a review. Genes 9 (11): 1-19.

Romay, M.C., R.A. Malvar, L. Campo, A. Alvarez, J. MorenoGonzales, A. Ordas and P. Revilla. 2010. Climatic and Genotypic Effects for Grain Yield in Maize under Stress Conditions. Crop Sci. 50 (1): 51-58.

Seiler, G. and C.C. Jan. 2010. Basic information. In: Genetics, genomics and breeding of sunflower, ed. Hu, J. Seiler, G. and Kole, C., 1-40, Enfield, New Hampshire, USA, CRC Press.

Solonechnyi, P., N. Vasko, A. Naumov, O. Solonechnaya, O. Vazhenina, O. Bondareva and Y. Logvinenko. 2015. GGE biplot analysis of genotype by environment interaction of spring barley varieties. Zemdirbyste-Agriculture 102 (4): 431-436.

Stojaković, M., B. Mitrović, M. Zorić, M. Ivanović, D. Stanisavljević, A. Nastasić and D. Dodig. 2015. Grouping pattern of maize test locations and its impact on hybrid zoning. Euphytica 204 (2): 419-431.

Temesgen, A., K. Mammo and L. Dagnachew. 2014. Genotype by Environment Interaction $(\mathrm{G} \times \mathrm{E})$ and Grain Yield Stability Analysis of Ethiopian Linseed and Niger Seed Varieties. Journal of Applied Biosciences 80: 7093-7101.
Yan, W. 2001. GGE biplot: a windows application for graphical analysis of multi environment trial data and other types of two-way data. Agron J. 93: 1-11.

Yan, W. and C. Rajcan. 2002. Biplot analysis of test sites and trait relations of Soybean in Ontario. Crop Sci. 42: 11-20.

Yan, W. and M.S. Kang. 2003. GGE biplot analysis: A graphical tool for breeders, geneticists and agronomists. CRC Press, Boca Raton, FL, USA, p. 1-271.

Yan, W. and N.A. Tinker. 2006. Biplot analysis of multienvironment trial data principles and application. Canadian Journal of Plant Science, 86(3): 623-645.

Yan, W., M.S. Kang, B. Ma, S. Woods and P.L. Cornelius. 2007. GGE Biplot vs. AMMI analysis of genotype-by-environment data. Crop Sci. 47: 643-655.

Yan, W. 2014. Crop variety trials: data management and analysis. Wiley-Blackwell, New York, $360 \mathrm{p}$.

Zobel, R.W., M.J. Wright and H.G. Gauch. 1988. Statistical analysis of yield trial. Agron J. 80: 388-393. 